\title{
Особенности агрессивности младших подростков с разным уровнем личностной тревожности
}

\author{
Зоя А. Прошкина, Галина П. ЗвезАина* \\ Аонской госуаарственный технический университет, г. Ростов-на-Аону, Россия \\ *E-mail: galzvezdina@yandex.ru
}

\begin{abstract}
Аннотация
Статья посвящена изучению агрессивности млаАших подростков с разным уровнем мичностной тревожности. Во введении актуализирована проблема изучения половозрастных различий агрессивности млаАших поАростков С Разным Уровнем Аичностной тревожности.

В основной части работы осуществлен анализ зарубежных и отечественных исследований, касающихся темы агрессивности и тревожности, особенностей социализации Аанной возрастной группы, фоормирования генАерной иАентичности в м^аАшем полростковом возрасте. ПривеАены и проанализированы внешние причины и условия формирования агрессивных реакций м^аАших поАростков обоего пола с разным уровнем мичностной тревожности в ответ на предьявляемые к ним средовые требования. Проведено эмпирическое исследование с применением психодиагностических методик Ч. А. Спилбергера. А. Басса и А. Аарки, Э. Вагнера; полученные Аанные проанализированы с применением методов математической статистики.
\end{abstract}

Результаты проведенного эмпирического исслеАования позволили установить статистически Аостоверные различия в проявлениях агрессивности млаАших поАростков разного пола со схоАным Уровнем Аичностной тревожности, а также в проявлениях агрессивности млаАших поАростков с разным уровнем Аичностной тревожности. Были установлены статистически Аостоверные связи проявлений агрессивности миаАшими поАростками-мальчиками в зависимости от уровня их Аичностной тревожности, и констатировано отсутствие таких связей у м^аАших поАростков-Аевочек. Установлено, что ^ичностная тревожность мальчиков м^аАшего подросткового возраста на среАнем уровне статистической значимости положительно связана с «поАозрительностью» и «вражАебностью», у Аевочек таких связей не обнаружено. САеланы выводы о проявлениях агрессивности у млаАших подростков разного пола с разным уровнем мичностной тревожности.

\section{КАючевые САова}

возраст, пол, мАаАшие поАростки, Аичностная тревожность, агрессивность, враждебность, фризическая агрессия, вербальная агрессия, косвенная агрессия, негативизм 
Аля цитирования: Прошкина З. А., ЗвезАина Г. П. Особенности агрессивности м^аАших поАростков с разным уровнем Аичностной тревожности // Северо-Кавказский психологический вестник. 2020. № 18/2. C. 44-64. doi: 10.21702/ncpb.2020.2.4

\title{
Features of aggressiveness of younger adolescents with different levels of personal anxiety
}

\author{
Zoya A. Proshkina, Galina P. Zvezdina* \\ Don State Technical University, Rostov-on-Don, Russia \\ *Corresponding author. E-mail: galzvezdina@yandex.ru
}

\begin{abstract}
The article is devoted to the study of the psychological characteristics of younger adolescents with different levels of personal anxiety. In the introduction, the problem of studying age and sex differences in the aggressiveness of younger adolescents with different levels of personal anxiety is updated.

In the main part of the work, the analysis of foreign and domestic studies concerning the topic of aggressiveness and anxiety, the peculiarities of socialization of this age group, the formation of gender identity in early adolescence is carried out. The external causes and conditions for the formation of aggressive reactions (in response to the environmental requirements) in younger adolescents of both sexes with different levels of personal anxiety are presented and analyzed. An empirical study was carried out using the psychodiagnostic techniques of Ch. D. Spielberger, A. H. Buss and A. Durkee, and E. Wagner, the data obtained are analyzed using the methods of mathematical statistics. The results of the empirical study made it possible to establish statistically significant differences in the manifestations of aggressiveness in younger adolescents of different sexes with a similar level of personal anxiety, as well as in the manifestations of aggressiveness in same-sex younger adolescents with different levels of personal anxiety. In addition, statistically reliable connections were established between the manifestations of aggression by younger male adolescents, depending on the level of their personal anxiety, and the absence of such connections was stated in younger female adolescents. It was found that the personal anxiety of young adolescent boys at the average level of statistical significance is positively associated with "suspicion" and "hostility"; no such connections were found in girls. Conclusions are drawn about the manifestations of aggressiveness in younger adolescents of different sexes with different levels of personal anxiety.
\end{abstract}

\section{Keywords}

age, gender, younger adolescents, personal anxiety, aggressiveness, hostility, physical aggression, verbal aggression, indirect aggression, negativism 
ОБЩАЯ ПСИХОЛОГИЯ, ПСИХОЛОГИЯ ЛИЧНОСТИ

For citation: Proshkina Z. A., Zvezdina G. P. Features of aggressiveness of younger adolescents with different levels of personal anxiety. Severo-Kavkazskii psikhologicheskii vestnik = North-Caucasian Psychological Bulletin, 2020, no. 18/2, pp. 44-64. doi: 10.21702/ ncpb.2020.2.4 (in Russ.).

\section{ВВЕДЕНИЕ}

Актуальность изучения проблемы проявления у младших подростков агрессивности и тревожности обусловлена, во-первых, возрастными особенностями 11-12-летних респондентов, связанными с гормональной перестройкой организма и особенно сильными и слабо контролируемыми эмоциональными всплесками, а во-вторых - необходимостью понимания педагогами и родителями того, каким образом можно помочь своим детям преодолеть этот кризисный период развития, не растеряв своих эмоциональных ресурсов и приобретя уверенность и эмоциональную стабильность на выходе из подростничества.

Особенно интересны в этом плане различия в проявлениях агрессивности у мальчиков и девочек младшего подросткового возраста, когда речь идет об эмоциональных состояниях, имеющих своей основой физиологические процессы. Можно предположить, что, в силу своих природно-обусловленных различий, мальчики и девочки будут по-разному проживать этот период взросления и, соответственно, по-разному реагировать, как на стимулы внешней среды, так и на свои собственные внутренние изменения.

В современной российской реальности у ребят, относящихся к рассматриваемой возрастной категории, существует и появляется достаточно внешних стимулов, на которые и взрослый человек с устоявшейся психикой мог бы отреагировать по-разному, в зависимости от степени своей психологической устойчивости и динамических особенностей нервной системы (стрессоустойчивости, способности к восстановлению ресурсов и др.). У подростков, особенно у младших подростков, все системы организма находятся в стадии реструктуризации, и это отнюдь не добавляет стабильности в их реагирование на вызовы, предлагаемые реальностью.

Так, в частности, развитие новых технологий, всё более ускоряющаяся и прогрессирующая жизнь в условиях развивающегося социума, как во всём мире в целом, так и в нашей стране в частности, требуют от школы внедрения и развития всё более и более прогрессивных методов обучения и воспитания и более жесткого стандарта проверки сформированности универсальных учебных действий (УУД).

Единый государственный экзамен, в форме которого проводится государственная итоговая аттестация по образовательным программам среднего общего образования, требует от учащихся, кроме демонстрации знаний 
и навыков, усвоенных в процессе обучения в школе, еще и высокой стрессоустойчивости, умения преодолевать тревогу, возникающую в стрессогенных ситуациях, связанных с различными аспектами обучения и проверки знаний.

Начиная с 2015 г. в рамках создаваемой в России, в соответствии с программой развития образования на 2013-2020 гг., национальной системы оценки качества образования и согласно графику Рособрнадзора проводятся Всероссийские проверочные работы (ВПР), представляющие собой единые стандартизированные контрольные работы.

Несмотря на то, что участие школ в проведении ВПР было добровольным, ситуация экзамена сама по себе для учеников младшей и средней школы является достаточно стрессогенной, и в ней вполне возможны проявления тревоги и агрессии.

Повышение требований к школьникам, как и ужесточение процедуры проверки их знаний и универсальных умений, неизбежно влечет за собой реакции, проявляющиеся на всех трех уровнях: когнитивном, эмоциональном и поведенческом. Так, необходимость усваивать большие объемы информации, осваивать на практике новые, постоянно развивающиеся, информационные технологии, неизбежно приводит к изменениям в эмоциональной сфере (тревога, связанная с ситуациями усвоения и проверки знаний, с различными аспектами взаимодействия в классе, с самоопределением и самооценкой), проявляющимся также и на уровне поведения (конфликтность, агрессивность и т.д.).

Агрессивность, так же, как и тревожность, неизбежно сопровождает процесс межличностного взаимодействия в школе, учитывая включенность младшего подростка во взаимодействие с одноклассниками, педагогами, родителями - в те взаимоотношения, в которых, с одной стороны, формируется его отношение к событиям и ситуациям, а с другой стороны-его самооценка, отношение к себе, к собственным проявлениям и поведению, закрепляются определенные поведенческие паттерны и эмоциональные реакции. На этом этапе очень важно понять, что происходит с подростком, помочь ему в эмоциональном преодолении сложных для него ситуаций, в формировании наиболее адекватных и экологичных способов реагирования, как для него самого, так и для его социального окружения.

С этой целью нами было проведено исследование различий в специфике проявления у младших подростков разного пола агрессивности, связанной с уровнем их личностной тревожности.

Анализ литературных источников, посвященных тревожности и агрессивности младших подростков, показал, что как отечественные (Л. С. Выготский, Д. Б. Эльконин, А. В. Петровский, И. Г. Малкина-Пых, и др.) [1, 2, 3, 4], так и зарубежные авторы (3. Фрейд, Э. Г. Эриксон, R. Ader, N. Cohen, E. Meumann, и др.) $[5,6,7]$ сходятся в определении младшего подросткового возраста как 
периода социализации, включения в различного рода отношения со своим окружением, поиска своего места в социуме, более или менее успешного усвоения правил и норм, принятых в обществе [8]. Именно в этом возрасте формируется самооценка (Л. Ф. Анн, О. В. Хухлаева) [9], а вместе с ней-уровень притязаний, лидерские качества, а также такие свойства эмоциональной сферы личности, как агрессивность (Г. П. Звездина, М. Ю. Елагина, Л. М. Нургалимова, Г. Г. Парфилова) $[10,11]$ (которая может проявляться как асоциальными, так и социально одобряемыми способами) и тревожность (Ю. Б. Горбатова, М. Е. Питанова, С. А. Амбалова, М. И. Бекоева, С. А. Бадоева, А. М. Волкова, и др.) $[12,13,14]$. Баланс этих составляющих определяет стиль поведения человека: будет он стремиться к достижению поставленной цели (мотивация достижения), либо будет пытаться всеми возможными способами избегать ситуаций, предполагающих ту или иную степень риска (мотивация избегания неудачи) [15]. Учитывая все перечисленные новообразования младшего подросткового возраста, его можно считать неким водоразделом, переходным периодом между детством и отрочеством. Гендерная идентичность, являясь одним из ключевых психологических образований младшего подросткового периода [16, 17], во многом детерминирует специфику проявления эмоциональных реакций и состояний младших подростков разного пола, в том числе тревожности и агрессивности.

Агрессивность в данном контексте рассматривается нами как свойство личности, а агрессия - как акт поведения. Данные понятия могут быть поняты в контексте психологического анализа мотивационно-потребностной сферы личности.

Тревожность - это состояние эмоционального дискомфорта, ожидания неблагополучия, предчувствия опасности, связанное с фрустрацией удовлетворения значимых потребностей, возникающее в ситуациях неопределенной опасности, характеризующееся переживанием беспокойства, страха, тревоги и прогнозом неблагоприятного развития событий. Как личностное образование или как свойство темперамента, обусловленное слабостью нервных процессов, тревожность - это индивидуальная психологическая особенность, проявляющаяся в склонности человека к частым и интенсивным переживаниям состояния тревоги, а также в низком пороге его возникновения [18].

Давая определение термину «агрессия», одни исследователи, в основном, концентрировали внимание на негативных аспектах этого явления (Л. С. Выготский, Б. Г. Мещеряков, В. П. Зинченко, Р. Бэрон, Д. Ричардсон, и др.) [см. 18, 19], другие, кроме негативных, учитывали ее позитивные и конструктивные аспекты (Э. Фромм, К. М. Галкова) [20, 21]. Среди причин формирования и стремления проявлять агрессивность в ее негативных аспектах младшими подростками, исследователи называют особенности семейного 
воспитания, влияние социального окружения, эмоциональные и личностные особенности самих подростков и т. д. (Л. М. Нургалимова, Г. Г. Парфилова, С. А. Амбалова, М. И. Бекоева, и др.) $[11,13]$.

Ряд исследователей считают, что как тревожность, так и агрессия неизбежно сопровождают процесс адаптации школьника к меняющимся требованиям, предъявляемым к нему новой образовательной системой (Н. А. Литвиненко, М. А. Гасилина) [22]. Одни исследователи связывают повышенный уровень тревожности как причину агрессивности младших подростков с особенностями семейного воспитания и семейной ситуации (С. А. Амбалова, М. И. Бекоева) [13], другие - с требованиями школьной среды и необходимостью соответствовать ожиданиям педагогов, родителей и сверстников (А. Бандура, Р. Уолтерс, L. J. Garcia-Lopez, M. do Ceu Salvador, A. De Los Reyes) [23, 24]. При этом все авторы сходятся в том, что повышенный уровень тревожности (чем бы она ни была детерминирована) напрямую связан с повышенной агрессивностью различной направленности, что негативно сказывается как на эмоциональном состоянии младшего подростка, так и на успешности его адаптации к условиям социальной и семейной среды [25].

\section{МЕТОДЫ}

Методическими и теоретическими предпосылками исследования являются теории развития личности ребенка на различных возрастных этапах, как зарубежные (3. Фрейд, Э. Эриксон, Ж. Пиаже, Р. Адер и др.) $[5,6,7]$, так и отечественные (Л. С. Выготский, Д. Б. Эльконин, А. В. Петровский и др.) [1, 2, 3]; работы отечественных и зарубежных ученых, посвященные изучению природы проявления тревожности (3. Фрейд, Э. Фромм, А. М. Прихожан и др.) $[5,18,19,20]$ и агрессивности (Э. Фромм, А. Басс, Р. Бэрон, Д. Ричардсон, А. Бандура, Р. Уолтерс и др.) [5, 19, 23]; исследования, посвященные изучению взаимной детерминированности тревожности и агрессивности младших подростков (С. Ю. Тарасова, К. М. Галкова, Ю. Б. Горбатова, М. Е. Питанова и др.) $[12,21,26]$; исследования, касающиеся формирования гендерной идентичности в младшем подростковом возрасте (Н. Ю. Рымарев, Н. П. Ковалева, М. Ю. Кузьмин, И. А. Конопак, Е. S. Watterson и др.) $[16,17,27,28]$.

Целью проведенного нами эмпирического исследования стало установление различий в уровне и специфике проявлений агрессивности у младших подростков с разным уровнем личностной тревожности с учетом их половой принадлежности, объектом - агрессивность и личностная тревожность младших подростков, предметом - связь агрессивности и уровня личностной тревожности младших подростков с учетом их половой принадлежности. Выборку составили младшие подростки в возрасте 11-12 лет в количестве 80-ти человек: 40 мальчиков и 40 девочек. 
ОБЩАЯ ПСИХОЛОГИЯ, ПСИХОЛОГИЯ ЛИЧНОСТИ

Нами были выдвинуты гипотетические предположения о том, что младшие подростки разного пола различаются особенностями проявления агрессивности и личностной тревожности, при этом существует связь между агрессивностью и уровнем личностной тревожности младших подростков, имеющая разную специфику у респондентов разного пола.

Для достижения поставленной цели и проверки выдвинутых гипотез нами было разработано и проведено эмпирическое исследование, включающее в себя следующие методы:

- психологическое тестирование;

- количественный анализ результатов проведенной диагностики с применением методов математической статистики.

Для реализации эмпирического исследования были применены следующие психодиагностические методики. С целью выявления уровня личностной тревожности младших подростков была применена методика «Шкала тревоги Спилбергера», для определения уровня и специфики агрессивности младших подростков была применена методика «Опросник враждебности Басса - Дарки» [29], для изучения склонности к явному агрессивному поведению младших подростков применялась проективная методика исследования личности «Hand Test» Э. Вагнера в адаптации Т. Н. Курбатовой [30], для анализа результатов эмпирического исследования были применены такие методы математической статистики, как одновыборочный статистический критерий нормальности распределения данных Колмогорова - Смирнова, непараметрический U-критерий Манна - Уитни для независимых выборок и линейный регрессионный анализ [4].

Исследование проводилось в два этапа. На первом этапе выборка была разделена на 4 группы - мальчики и девочки были разделены на 2 категории в зависимости от выявленного у них уровня личностной тревожности. Результаты деления выборки на группы представлены на рисунке 1.

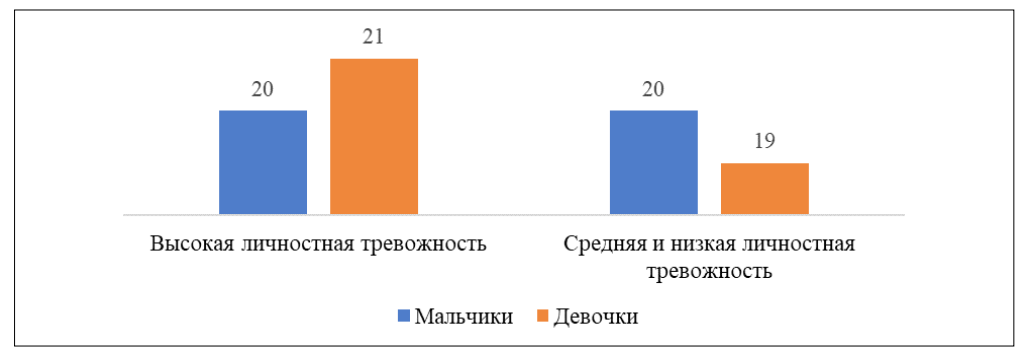

Рисунок 1. Количественное соотношение м^алших полростков с разным уровнем тревожности, в целых числах (тест Спилбергера) 
На втором этапе проводилось исследование агрессивности младших подростков с разным уровнем личностной тревожности с учетом их половой принадлежности.

\section{РЕЗУЛЬТАТЫ}

Результаты теста «Опросник враждебности Басса - Дарки», полученные для групп младших подростков разного пола с высоким уровнем личностной тревожности, в процентном соотношении представлены на рисунке 2. Из диаграммы, приведенной на рисунке, видно, что ведущей составляющей агрессивности младших подростков обоего пола с высоким уровнем личностной тревожности является негативизм, выраженный у мальчиков $(62,00 \%)$ несколько сильнее, пусть и статистически незначимо, чем у девочек (59,00\%).

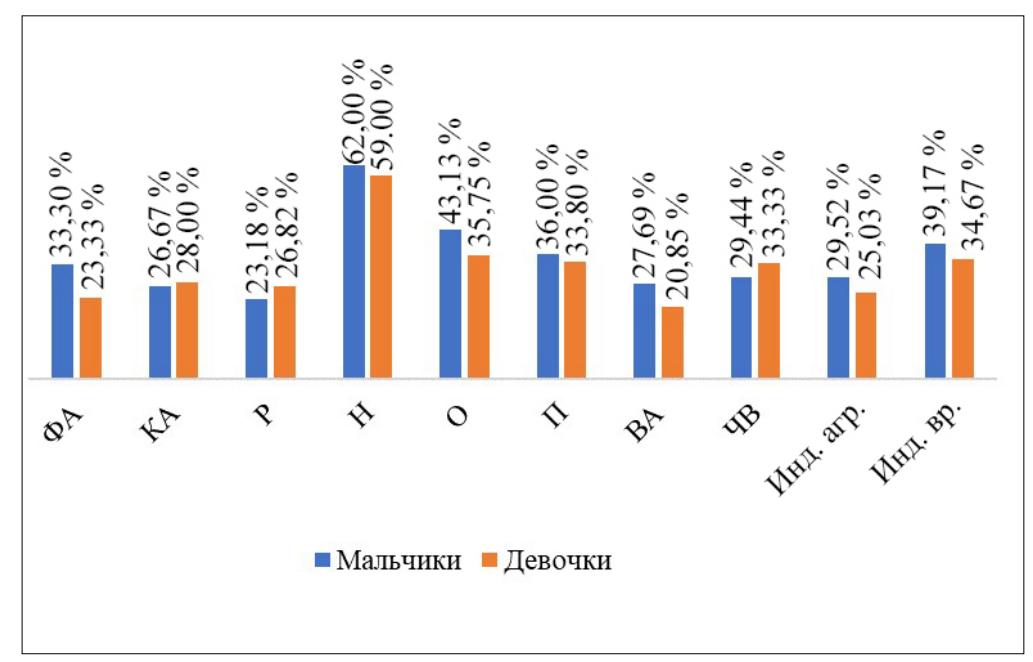

Рисунок 2. Показатели агрессивности и вражАебности млаАших полростков с высоким уровнем мичностной тревожности - в процентах (тест Басса-Аарки)

На рисунке 3 представлены результаты проективной методики «Hand Test», дающей представление об особенностях взаимодействия респондентов с высоким уровнем личностной тревожности с окружающим миром и социумом, в том числе - и об их агрессивности.

Из приведенной на рисунке 3 диаграммы следует, что к проявлению открытой агрессии не склонны ни мальчики (фактор I = -1,25), ни девочки (фактор I = -0,90) с высоким уровнем личностной тревожности. 


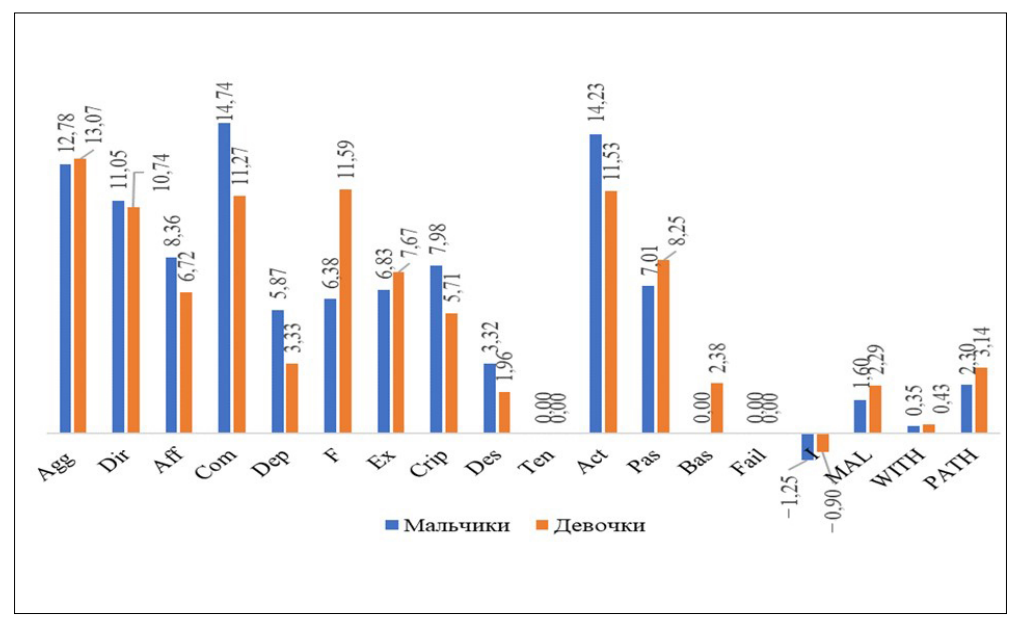

Рисунок 3. Результаты методики «Hand Test») младших подростков с высоким уровнем Аичностной тревожности

В таблице 1 представлены результаты сравнительного анализа агрессивности младших подростков разного пола с высоким уровнем личностной тревожности.

Таблица 1

Результаты сравнительного анализа особенностей агрессивности млаАших поАростков разного пола с высоким уровнем Аичностной тревожности

\begin{tabular}{|l|c|c|c|}
\hline \multicolumn{1}{|c|}{ Показатели } & Пол & Ср. знач. & $\begin{array}{c}\text { Уровень } \\
\text { значимости }\end{array}$ \\
\hline \multirow{2}{*}{$\begin{array}{l}\text { Косвенная агрессия (тест } \\
\text { Басса-Аарки) }\end{array}$} & Мальчики & 2,40 & \multirow{2}{*}{$0,037^{*}$} \\
\cline { 2 - 3 } & Аевочки & 2,52 & \\
\hline \multirow{2}{*}{$\begin{array}{l}\text { Категория «Ваз»- } \\
\text { галмюцинации (Hand Теst) }\end{array}$} & Мальчики & 0,00 & \multirow{2}{*}{$0,021^{*}$} \\
\cline { 2 - 3 } & Аевочки & 2,38 & \\
\hline
\end{tabular}


Уровень косвенной агрессии, при невысоких показателях, как у мальчиков $(26,67 \%)$, так и у девочек $(28,00 \%)$ достоверно различается на среднем уровне статистической значимости ( $p=0,037)$. Также выявлено различие на среднем уровне статистической значимости $(p=0,021)$ в показателях категории Bas (галлюцинации), включающей в себя ответы невероятного, необычного, страшного и пугающего содержания. Значимость различий по этой категории объясняется тем, что мальчики таких ответов не дали совсем (Bas $=0,00)$, а девочки дали небольшое количество подобных ответов (Bas $=2,38)$.

Результаты теста «Опросник враждебности Басса - Дарки», полученные для групп младших подростков разного пола со средним и низким уровнем личностной тревожности, в процентном соотношении представлены на рисунке 4.

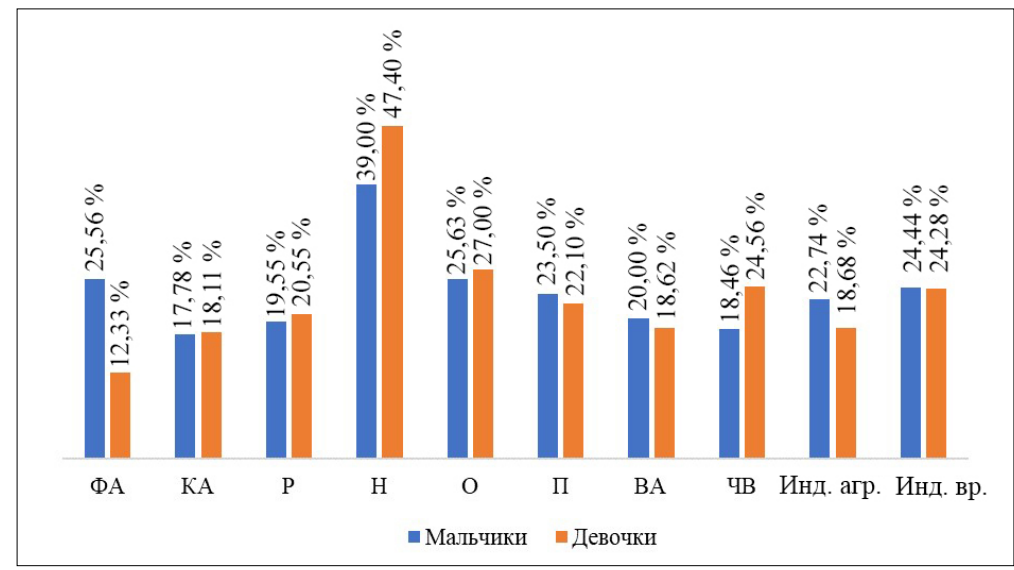

Рисунок 4. Показатели агрессивности и вражАебности млаАших поАростков со среАним и низким уровнем Аичностной тревожности - в процентах (тест Басса-Аарки)

Из диаграммы, представленной на рисунке 4, видно, что ведущей составляющей агрессивности младших подростков обоего пола со средним и низким уровнем личностной тревожности, также, как и у их сверстников с высоким уровнем личностной тревожности, является негативизм; только здесь, в отличие от младших подростков с высоким уровнем личностной тревожности, он выражен сильнее у девочек (47,40\%), чем у мальчиков (39,00\%). При этом у младших подростков обоего пола со средним и низким уровнем личностной тревожности эти показатели ниже, чем у их сверстников того же пола, но с высоким уровнем личностной тревожности. 
Результаты проективной методики «Hand Test» представлены диаграммой на рисунке 5 .

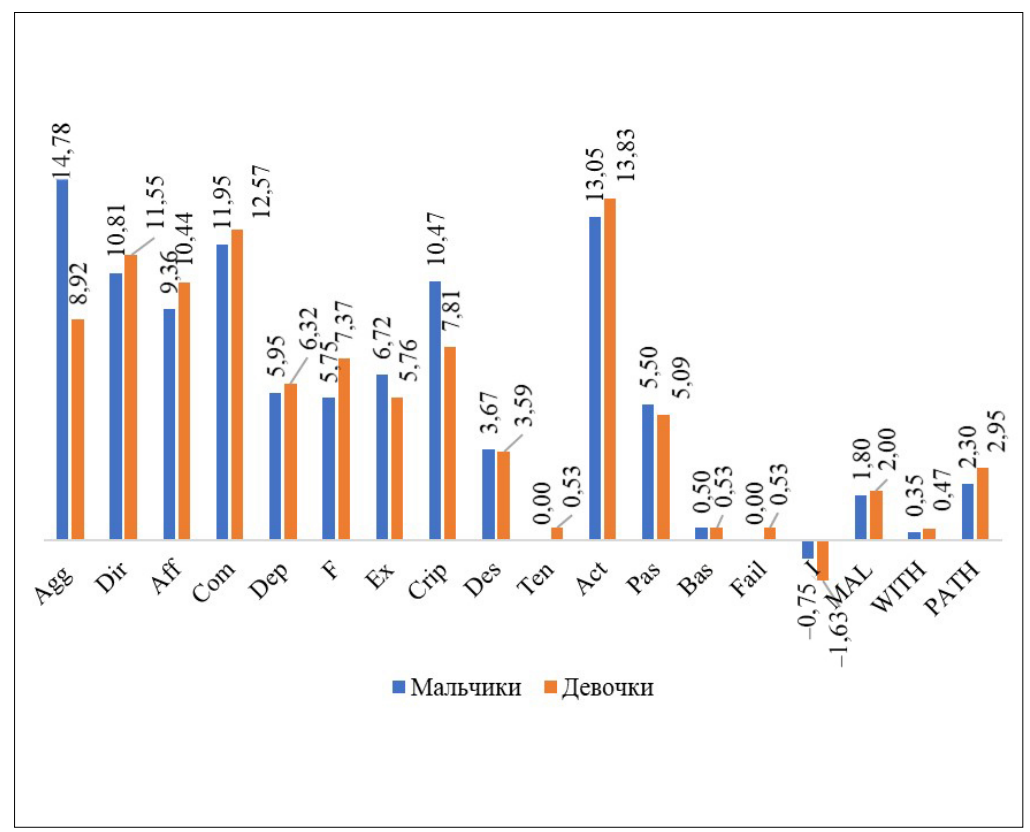

Рисунок 5. Результаты метолики «Hand Теst» млаАших полростков со среАним И низким Уровнем Аичностной тревожности

Из приведенной на рисунке 5 диаграммы следует, что склонности к проявлению открытой агрессии не отмечается ни у мальчиков (фактор I = -0,75), ни у девочек (фактор I = -1,63) со средним и низким уровнем личностной тревожности.

В таблице 2 представлены результаты сравнительного анализа агрессивности младших подростков разного пола со средним и низким уровнем личностной тревожности.

Выявлены различия на среднем уровне статистической значимости по шкале «физическая агрессия» теста Басса - Дарки $(p=0,023)$ между показателями младших подростков разного пола со средним и низким уровнем личностной тревожности; также выявлены различия на высоком уровне статистической значимости $(p=0,005)$ между результатами мальчиков и девочек со средним и низким уровнем личностной тревожности по категории Agg (агрессивность). 
Результаты сравнительного анализа особенностей агрессивности млаАших поАростков разного пола со среАним И низКим УровнеМ Аичностной тревожности

\begin{tabular}{|l|c|c|c|}
\hline \multicolumn{1}{|c|}{ Показатели } & Пол & Ср. знач. & $\begin{array}{c}\text { Уровень } \\
\text { значимости }\end{array}$ \\
\hline \multirow{2}{*}{$\begin{array}{l}\text { Физическая агрессия } \\
\text { (тест Басса-Аарки) }\end{array}$} & Мальчики & 2,30 & \multirow{2}{*}{$0,023^{*}$} \\
\cline { 2 - 3 } & Аевочки & 1,11 & \multirow{2}{*}{$0,005^{* *}$} \\
\hline $\begin{array}{l}\text { Категория } \\
\text { «Agg»-агрессивность } \\
\text { (Hand Теst) }\end{array}$ & Мальчики & 14,78 & \\
\cline { 2 - 3 } & Аевочки & 8,92 & \\
\hline
\end{tabular}

В таблице 3 и на рисунке 6 представлены результаты анализа данных групп младших подростков женского пола с разным уровнем личностной тревожности.

Таблица 3

Результаты сравнительного анализа особенностей агрессивности млаАших ПоАростКов-АевочеК с разныМ Уровнем Аичностной тревожности

\begin{tabular}{|c|c|c|c|}
\hline Показатели & $\begin{array}{c}\text { Уровень } \\
\text { тревожности }\end{array}$ & Ср. знач. & $\begin{array}{c}\text { Уровень } \\
\text { значимости }\end{array}$ \\
\hline \multirow{2}{*}{$\begin{array}{l}\text { Физическая агрессия } \\
\text { (тест Басса-Аарки) }\end{array}$} & Высокий & 2,10 & \multirow{2}{*}{$0,047^{*}$} \\
\hline & $\begin{array}{c}\text { Низкий } \\
\text { и средний }\end{array}$ & 1,11 & \\
\hline \multirow{2}{*}{$\begin{array}{l}\text { Подозрительность (тест } \\
\text { Басса - Аарки) }\end{array}$} & Высокий & 3,38 & \multirow{2}{*}{$0,015^{*}$} \\
\hline & $\begin{array}{c}\text { Низкий } \\
\text { и средний }\end{array}$ & 2,21 & \\
\hline \multirow{2}{*}{$\begin{array}{l}\text { Чувство вины (тест Басса- } \\
\text { Аарки) }\end{array}$} & Высокий & 3,00 & \multirow{2}{*}{$0,027^{*}$} \\
\hline & $\begin{array}{c}\text { Низкий } \\
\text { и средний }\end{array}$ & 2,21 & \\
\hline \multirow{2}{*}{$\begin{array}{l}\text { Индекс вражАебности } \\
\text { (тест Басса-Аарки) }\end{array}$} & Высокий & 6,24 & \multirow[b]{2}{*}{$0,015^{*}$} \\
\hline & $\begin{array}{c}\text { Низкий } \\
\text { и среАний }\end{array}$ & 4,37 & \\
\hline
\end{tabular}


Выявлено 4 достоверных различия на среднем уровне статистической значимости в отношении таких показателей теста Басса - Дарки, как «физическая агрессия» $(p=0,047)$, «подозрительность» $(p=0,015)$, «чувство вины» $(p=0,027)$ и «индекс враждебности» $(p=0,015)$.

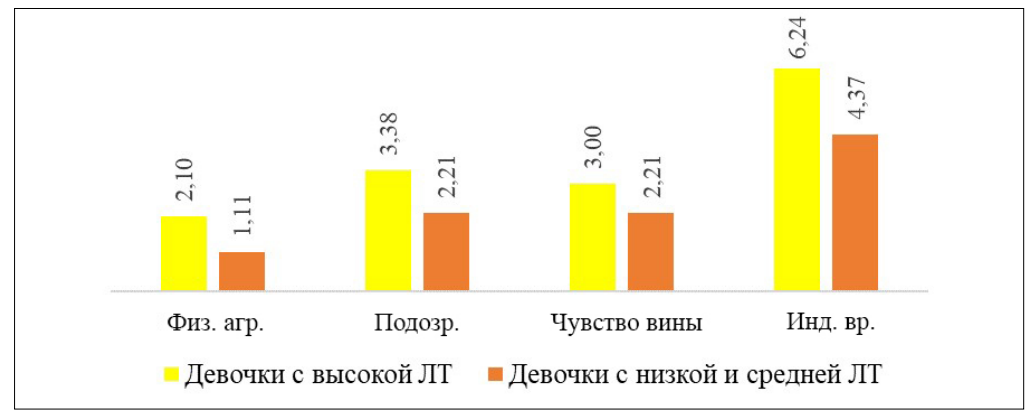

Рисунок 6. Различия в агрессивности м^аАших полростков женского пола с разным уровнем личностной тревожности (тест Басса-Аарки)

В таблице 4 и на рисунке 7 представлены результаты анализа данных групп младших подростков мужского пола с разным уровнем личностной тревожности.

Таблица 4

Результаты сравнительного анализа особенностей агрессивности млаАших поАростков-мальчиков С разным уровнем Аичностной тревожности

\begin{tabular}{|c|c|c|c|}
\hline Показатели & $\begin{array}{c}\text { Уровень } \\
\text { тревожности }\end{array}$ & Ср. знач. & $\begin{array}{c}\text { Уровень } \\
\text { значимости }\end{array}$ \\
\hline \multirow{2}{*}{$\begin{array}{l}\text { Негативизм (тест Басса- } \\
\text { Аарки) }\end{array}$} & Высокий & 3,10 & \multirow[b]{2}{*}{$0,008^{* *}$} \\
\hline & $\begin{array}{c}\text { Низкий } \\
\text { и средний }\end{array}$ & 1,95 & \\
\hline \multirow{2}{*}{$\begin{array}{l}\text { Обила (тест Басса- } \\
\text { Аарки) }\end{array}$} & Высокий & 3,45 & \multirow{2}{*}{$0,001^{* *}$} \\
\hline & $\begin{array}{c}\text { Низкий } \\
\text { и среАНий }\end{array}$ & 2,05 & \\
\hline \multirow{2}{*}{$\begin{array}{l}\text { Подозрительность (тест } \\
\text { Басса-Аарки) }\end{array}$} & Высокий & 3,60 & \multirow[b]{2}{*}{$0,023^{*}$} \\
\hline & $\begin{array}{c}\text { Низкий } \\
\text { и среАний }\end{array}$ & 2,35 & \\
\hline \multirow{2}{*}{$\begin{array}{l}\text { Вербальная агрессия } \\
\text { (тест Басса-Аарки) }\end{array}$} & Высокий & 3,60 & \multirow{2}{*}{$0,046 *$} \\
\hline & $\begin{array}{c}\text { Низкий } \\
\text { и среАний }\end{array}$ & 2,60 & \\
\hline $\begin{array}{l}\text { Индекс враждебности } \\
\text { (тест Басса - Аарки) }\end{array}$ & Высокий & 7,05 & $0,000^{* *}$ \\
\hline
\end{tabular}


На высоком уровне статистической значимости выявлены различия в показателях по шкалам теста Басса - Дарки, таких, как «негативизм» $(p=0,008)$, «обида» $(p=0,001)$ и «индекс враждебности» $(p=0,000)$.

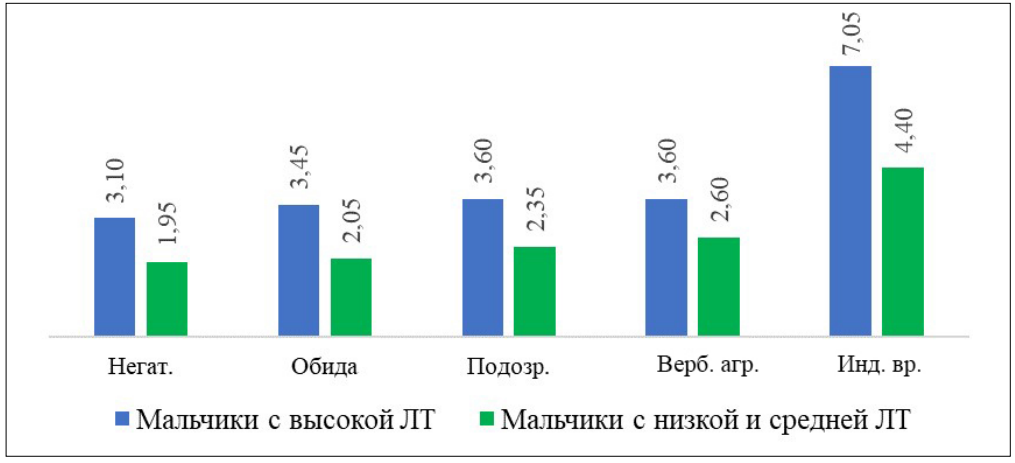

Рисунок 7. Различия в агрессивности м^аАших поАростков мужского пола с разным уровнем личностной тревожности (тест Басса-Аарки)

В таблице 5 приведены результаты линейного регрессионного анализа данных групп младших подростков-мальчиков, позволившего определить связь их личностной тревожности с особенностями проявления их агрессивности. Линейный регрессионный анализ, проведенный относительно данных, полученных для выборки девочек, не показал статистически достоверных связей между проявлениями их агрессивности и уровнем личностной тревожности.

Таблица 5

Результаты линейного регрессионного анализа Аанных млаАших поАростков Мужского пола с разным Уровнем Аичностной тревожности

\begin{tabular}{|c|c|c|}
\hline Влияющие переменные & Связь & Знач. (p) \\
\hline Подозрительность (тест Басса-Аарки) & 0,515 & $0,001^{* *}$ \\
\hline $\begin{array}{l}\text { Индекс вражАебности (тест Басса- } \\
\text { Аарки) }\end{array}$ & 0,604 & $0,000^{* *}$ \\
\hline
\end{tabular}

Согласно результатам проведенного линейного регрессионного анализа, личностная тревожность мальчиков младшего подросткового возраста на среднем уровне статистической значимости положительно связана с «подозрительностью» $(p=0,001)$ и «враждебностью» $(p=0,000)$, диагностируемыми при помощи теста Басса - Дарки. 
ОБЩАЯ ПСИХОЛОГИЯ, ПСИХОЛОГИЯ ЛИЧнОСТИ

\section{ОБСУЖДЕНИЕ РЕЗУЛЬТАТОВ}

И мальчики и девочки младшего подросткового возраста, как с высоким уровнем личностной тревожности (в большей степени), так и со средним и низким уровнем личностной тревожности (в меньшей степени) склонны к применению оппозиционных форм поведения, направленных обычно против авторитетных фигур (родителей, педагогов и т. д.), которые могут варьироваться от пассивного невыполнения требований до активного сопротивления и противоборства.

При этом к проявлению открытой агрессии не склонны ни мальчики, ни девочки, независимо от уровня личностной тревожности; у девочек с высокой личностной тревожностью, пусть статистически и незначимо, но склонность к проявлению открытой агрессии выражена несколько сильнее, чем у мальчиков, а у девочек со средним и низким уровнем личностной тревожности, наоборот, склонность к проявлению открытой агрессии выражена слабее, чем у их сверстников-мальчиков с таким же уровнем личностной тревожности. Девочки с высоким уровнем личностной тревожности более, чем мальчики со сходным уровнем личностной тревожности, склонны к проявлению косвенной (неявной, ненаправленной) агрессии, а также - к личностной дезадаптации.

Мальчики со средним и низким уровнем личностной тревожности более, чем девочки с таким же уровнем личностной тревожности, склонны к открытому проявлению агрессии в поведении и к использованию физической силы против других людей. Девочки со средним и низким уровнем личностной тревожности менее склонны применять физическую силу в конфликтах, более склонны доверять окружающим, меньше склонны обвинять себя, менее враждебно настроены по отношению к внешнему миру, чем девочки с высоким уровнем личностной тревожности. Мальчики со средним и низким уровнем личностной тревожности менее склонны практиковать оппозиционные формы поведения по отношению к авторитетным фигурам (родителям, педагогам и т. д.), меньше завидуют окружающим, не склонны огорчаться по поводу несправедливости мира к ним, и менее враждебны, чем мальчики с высоким уровнем личностной тревожности.

Чем выше уровень личностной тревожности мальчиков младшего подросткового возраста, тем они более недоверчивы и осторожны по отношению к окружающим, которые, как им кажется, могут причинить вред, что, в свою очередь, вызывает у них ответную враждебность. В отношении выборки девочек младшего подросткового возраста статистически достоверных связей между уровнем личностной тревожности и проявлениями агрессивности не выявлено. 


\section{Вывод}

Таким образом, мы можем констатировать факт полного подтверждения выдвинутого ранее предположения о том, что младшие подростки разного пола различаются особенностями проявления агрессивности и личностной тревожности; при этом существует связь между уровнем личностной тревожности и агрессивностью младших подростков, имеющая разную специфику у респондентов разного пола.

\section{ЛИТЕРАТУРА}

1. Выготский Л. С. Проблема возраста // Выготский Л. С. Собрание сочинений: В 6-ти т. М.: Педагогика, 1984. Т. 4. С. 244-268.

2. Эльконин Д. Б. К проблеме периодизации психического развития в детском возрасте // Вопросы психологии. 1971. № 4. С. 6-20.

3. Петровский В. А. Принцип ведущей деятельности и проблема личностно-образующих видов деятельности при переходе от детства к взрослости // Психологические условия и механизмы воспитания подростков. М., 1983. С. 20-33.

4. Малкина-Пых И. Г. Возрастные кризисы: Справочник практического психолога. М.: ЭКСМО, 2009. 1180 с.

5. Фрейд 3. Психология бессознательного: Сб. произведений / Сост., науч. ред., авт. вступ. ст. М. Г. Ярошевский. М.: Просвещение, 1990. 448 с.

6. Эриксон Э. Г. Детство и общество. СПб.: Ленато, АСТ, Фонд «Университетская книга», 1996. 592 с.

7. Ader R., Cohen N. Psychoneuroimmunology: Conditioning and stress // Annual Review of Psychology. 1993. Vol. 44. P. 53-85. DOI: 10.1146/annurev. ps.44.020193.000413

8. Байковская Н.А. Об исследовании способности к сочувствию и уровня развития моральных суждений у младших школьников // Вестник Московского государственного областного университета. Серия: Психологические науки. 2012. № 3. С. 41-47.

9. Хухлаева О. В. Психология подростка. М.: Академия, 2005. 160 с.

10. Звездина Г. П., Елагина М. Ю. Особенности профилактики жестокости и насилия в образовательной среде // Личность в культуре и образовании: психологическое сопровождение, развитие, социализация. 2015. № 3. С. 214-217.

11. Нургалимова Л. М., Парфилова Г. Г. Профилактика и преодоление агрессивности у подростков // Актуальные проблемы педагогики и психологии: Сборник научных трудов преподавателей, молодых ученых и студентов, посвященный 210-летию Казанского университета. Казань: Отечество, 2015. С. 236-239. 
12. Горбатова Ю. Б., Питанова М. Е. Школьная тревожность пятиклассников // Фундаментальные проблемы науки: Сборник статей Международной научно-практической конференции. Уфа: Аэтерна, 2016. С. 185-187.

13. Амбалова С. А., Бекоева М. И. К вопросу о психологических особенностях учебной деятельности и агрессивном поведении младших школьников // Азимут научных исследований: Педагогика и психология. 2016. T. 5, № 2. С. 183-185.

14. Бадоева С. А., Волкова А. М. Тревожность как негативный фактор в процессе обучения младших школьников // Дошкольное и начальное образование: современные методические подходы: Международная конференция «Чтения Ушинского». Ярославль: Ярославский государственный педагогический университет им. К. Д. Ушинского, 2015. С. 72-77.

15. Кривощекова О. В. Профилактика агрессивного поведения младших подростков как актуальное направление социально-педагогической деятельности // Безопасное детство как правовой и социально-педагогический концепт: Материалы II Всероссийской с международным участием научно-практической конференции. Пермь:Пермский государственный гуманитарно-педагогический университет, 2015. С. 138-140.

16. Ковалева Н. П. Развитие половой идентичности младших школьников и ее связь со структурно-содержательными характеристиками семьи: дисс. канд. психол. наук. СПб., 2015. 198 с.

17. Кузьмин М. Ю., Конопак И. А. Влияние структуры семьи на идентичность школьника // Известия Иркутского государственного университета. Серия: Психология. 2014. Т. 7. С. 28-41.

18. Прихожан А. М. Тревожность у детей и подростков: психологическая природа и возрастная динамика. М.: Московский психолого-социальный институт; Воронеж: НПО «МОДЭК», 2000. 304 с.

19. Бэрон Р., Ричардсон Д. Агрессия. СПб.: Питер, 2001. 352 с.

20. Фромм Э. Анатомия человеческой деструктивности. М.: Республика, 1994. 447 c.

21. Галкова К. М. Специфика агрессивности и тревожности у детей младшего школьного возраста в семьях с различными типами детско-родительских отношений // Вестник психофизиологии. 2015. № 3. С. 64-70.

22. Литвиненко Н. В., Гасилина М. А. Тревожность и агрессия как показатели проявлений дезадаптации детей 6-7 лет к образовательной среде дошкольной организации // Интернет-журнал «Мир науки». 2016. Т. 4, № 3. URL: http://mir-nauki.com/PDF/19PDMN316.pdf (дата обращения: 04.12.2020).

23. Бандура А., Уолтерс Р. Подростковая агрессия: Изучение влияния воспитания и семейных отношений. М.: Апрель-Пресс, 1999. 509 с. 
24. Garcia-Lopez L. J., do Ceu Salvador M., De Los Reyes A. Assessment of social anxiety in adolescents // Social anxiety and phobia in adolescents / Ed. by K. Ranta, A. La Greca, L. J. Garcia-Lopez, M. Marttunen. Springer, Cham, 2015. P. 121-150. DOI: 10.1007/978-3-319-16703-9 6 6

25. Ижаева М. М. Тревожность в младшем школьном возрасте // Современные проблемы инновационного развития науки: Сборник статей Международной научно-практической конференции. Уфа: ОМЕГА САЙНС, 2016. С. 159-161.

26. Тарасова С. Ю., Асриян А. А. Взаимосвязь тревожности и агрессивности школьников, обучающихся в образовательных организациях разного типа // Сборник статей «Межпоколенческие отношения: современный дискурс и стратегические выборы в психолого-педагогической науке и практике». М.: Психологический институт РAO, 2020. C. 271-275. DOI: 10.24411/9999-047A-2020-00077

27. Рымарев Н. Ю. Личностные особенности подростков с различной гендерной идентичностью: дисс. канд. психол. наук. Краснодар, 2006. 139 с.

28. Watterson E. S. Evaluative reactions to gender stereotype violations: A test of the gender intensification hypothesis: Doctoral Diss. (Psychology). Saint Louis University, 2012.

29. Батаршев А. В. Базовые психологические свойства и профессиональное самоопределение личности: Практическое руководство по психологической диагностике. СПб.: Речь, 2005. 208 с.

30. Курбатова Т. Н., Муляр О. И. Проективная методика исследования личности «Hand-тест»: Методическое руководство. СПб.: ИМАТОН, 2001. 64 с.

\section{REFERENCES}

1. Vygotskii L. S. The problem of age. In:Vygotskii L. S. Collected works. Moscow, Pedagogika, 1984. V. 4, pp. 244-268. (in Russ.).

2. Elkonin D. B. On the problem of periodization of psychological development in childhood. Voprosy psikhologii, 1971, no. 4, pp. 6-20. (in Russ.).

3. Petrovskii V. A. The principle of leading activity and the problem of personality-forming types of activity during the transition from childhood to adulthood. In: Psychological conditions and mechanisms of education of adolescents. Moscow, 1983, pp. 20-33. (in Russ.).

4. Malkina-Pykh I. G. Age crises. Handbook of a practical psychologist. Moscow, EKSMO, 2009. 1180 p. (in Russ.).

5. Freud S. Psychology of the unconscious: Collected works. Comp. and Sc. Ed. by M. G. Yaroshevskii. Moscow, Prosveshchenie, 1990. 448 p. (in Russ.).

6. Erikson E. H. Childhood and Society. St. Petersburg, Lenato, AST, “University Book" Foundation, 1996. 592 p. (in Russ.). 
7. Ader R., Cohen N. Psychoneuroimmunology: Conditioning and stress. Annual Review of Psychology, 1993, V. 44, pp. 53-85. DOI: 10.1146/annurev. ps.44.020193.000413

8. Baikovskaya N. A. On the study of the ability to sympathy and the level of development of moral judgments in primary school students. Vestnik Moskovskogo gosudarstvennogo oblastnogo universiteta. Seriya: Psikhologicheskie nauki = Bulletin of the Moscow Region State University. Series: Psychology, 2012, no. 3, pp. 41-47. (in Russ.).

9. Khukhlaeva O. V. Psychology of a teenager. Moscow, Akademiya, 2005. 160 p. (in Russ.).

10. Zvezdina G. P., Elagina M. Yu. Features of the prevention of cruelty and violence in the educational environment. Lichnost' $v$ kul'ture i obrazovanii: psikhologicheskoe soprovozhdenie, razvitie, sotsializatsiya, 2015, no. 3, pp. 214-217. (in Russ.).

11. Nurgalimova L. M., Parfilova G. G. Prevention and overcoming of aggressiveness in adolescents. In: Actual problems of pedagogy and psychology: Collection of scientific works of teachers, young scientists and students, dedicated to the 210th anniversary of Kazan University. Kazan, Otechestvo, 2015, pp. 236-239. (in Russ.).

12. Gorbatova Yu. B., Pitanova M. E. School anxiety in fifth graders. In: Fundamental problems of science: Collection of articles of the International Scientific and Practical Conference. Ufa, Aeterna, 2016, pp. 185-187. (in Russ.).

13. Ambalova S. A., Bekoeva M. I. On the question of the psychological characteristics of educational activity and aggressive behavior of younger schoolchildren. ANI: pedagogika i psikhologiya $=$ ASR: Pedagogy and Psychology, 2016, V. 5, no. 2, pp. 183-185. (in Russ.).

14. Badoeva S. A., Volkova A. M. Anxiety as a negative factor in the process of teaching younger students. In: Preschool and primary education: Modern methodological approaches: International conference "Reading of Ushinsky". Yaroslavl, Yaroslavl State Pedagogical University named after K. D. Ushinsky, 2015, pp. 72-77. (in Russ.).

15. Krivoshchekova O. V. Prevention of aggressive behavior in younger adolescents as an actual direction of social and pedagogical activity. In: Safe childhood as a legal and socio-pedagogical concept: Materials of the II AllRussian scientific-practical conference with international participation. Perm, Perm State Humanitarian Pedagogical University, 2015, pp. 138-140. (in Russ.).

16. Kovaleva N. P. The development of the gender identity of primary schoolchildren and its connection with the structural and meaningful characteristics of the family (Candidate Dissertation). St. Petersburg, 2015. 198 p. (in Russ.). 
17. Kuzmin M. Yu., Konopak I. A. The influence of family structure on the identity of a student. Izvestiya Irkutskogo gosudarstvennogo universiteta. Seriya: Psikhologiya = The Bulletin of Irkutsk State University. Series "Psychology", 2014, V. 7, pp. 28-41. (in Russ.).

18. Prikhozhan A. M. Anxiety in children and adolescents: Psychological nature and age-related dynamics. Moscow, Moscow Psychologic-Social Institute; Voronezh, MODEK, 2000. 304 p. (in Russ.).

19. Baron R., Richardson D. Aggression. St. Petersburg, Piter, 2001. 352 p. (in Russ.).

20. Fromm E. Anatomy of human destructiveness. Moscow, Respublika, 1994. 447 p. (in Russ.).

21. Galkova K. M. The specificity of aggressiveness and anxiety in primary school children in families with different types of parent-child relationships. Vestnik psikhofiziologii = Psychophysiology news, 2015, no. 3, pp. 64-70. (in Russ.).

22. Litvinenko N. V., Gasilina M. A. Anxiety and aggression as indicators of manifestations of maladjustment in 6-7 year old children to the educational environment preschool. Internet-zhurnal "Mir nauki" = World of Science, 2016, V. 4, no. 3. Available at: http://mir-nauki.com/PDF/19PDMN316.pdf (Accessed 04 December 2020). (in Russ.).

23. Bandura A., Walters R. Teenage aggression. Studying the influence of parenting and family relationships. Moscow, Aprel-Press, 1999. 509 p. (in Russ.).

24. Garcia-Lopez L. J., do Ceu Salvador M., De Los Reyes A. Assessment of social anxiety in adolescents. In: K. Ranta, A. La Greca, L. J. Garcia-Lopez, M. Marttunen (Eds.). Social anxiety and phobia in adolescents. Springer, Cham, 2015, pp. 121-150. DOI: 10.1007/978-3-319-16703-9 6

25. Izhaeva M. M. Anxiety at primary school age. In: Modern problems of innovative development of science: Collection of articles of the International scientific and practical conference. Ufa, OMEGA SAINS, 2016, pp. 159-161. (in Russ.).

26. Tarasova S. Yu., Asriyan A. A. The relationship between anxiety and aggressiveness of schoolchildren studying in educational institutions of various types. In: Intergenerational relations: modern discourse and strategic choices in psychological and pedagogical science and practice: Collection of articles. Moscow, Psychological Institute of the Russian Academy of Education, 2020, pp. 271-275. DOI: 10.24411/9999-047A-2020-00077 (in Russ.).

27. Rymarev N. Yu. Personal characteristics of adolescents with different gender identities (Candidate Dissertation). Krasnodar, 2006. 139 p. (in Russ.).

28. Watterson E. S. Evaluative reactions to gender stereotype violations: $A$ test of the gender intensification hypothesis (Doctoral Dissertation). Saint Louis University, 2012. 
ОБЩАЯ ПСИхолОГИЯ, ПСИхолОгИЯ личнОСти

29. Batarshev A. V. Basic psychological properties and personality self-determination: A practical guide to psychological diagnostics. St. Petersburg, Rech', 2005. 208 p. (in Russ.).

30. Kurbatova T. N., Mulyar O. I. Projective personality research method "Handtest". Methodical guidance. St. Petersburg, IMATON, 2001.64 p. (in Russ.). 